Artigo

\title{
As regras do jogo da morte encefálica
}

\author{
Juliana Lopes de Macedo \\ Universidade Federal do Pampa, Uruguaiense, RS, Brasil \\ julianamacedo@unipampa.edu.br
}

RESUMO: Em 1968 a comunidade médica internacional cunhou o conceito "morte encefálica" que passou a ser utilizado para diagnosticar pacientes que, até então, se encontravam na condição do que se conhecia como "coma irreversível". A partir desse momento, quando o cérebro não apresentasse mais nenhuma atividade biológica, porém, o coração permanecesse em funcionamento, estar-se-ia diante de um caso de morte encefálica. Para a medicina, isso implicou a possibilidade da realização de remoção de órgãos para cirurgias de transplantes, mas, além disso, também representou uma nova maneira de conceber a morte. O presente artigo analisa, a partir da realização de entrevistas com roteiro semiestruturado entre médicos envolvidos neste contexto, o processo de diagnóstico de morte encefálica e a negociação que se estabelece entre os diferentes atores sociais envolvidos neste processo de definição de morte.

PALAVRAS-CHAVE: Morte encefálica, transplantes de órgãos, Antropologia da Ciência. 


\section{Introdução}

A morte é um tema que abarca diversas esferas da vida social, como religião, direito, medicina. No entanto, por mais que cada uma dessas esferas tenha a sua definição para morte, na sociedade ocidental, quem detém o monopólio de identificar se uma pessoa está morta ou viva é a medicina ${ }^{1}$. Até a década de 1960, o indicador médico de morte era a parada cardiorrespiratória. Mas o que dizer, então, de alguém que tem atividade cardíaca, mas, mesmo assim, é considerado morto? Nesses casos, estamos diante da "nova morte", ou morte encefálica, um tipo de morte possibilitada por um contexto social muito específico, que envolve ciência, tecnologia, medicina e modernidade, e que promove uma fusão (ou confusão) entre corpo e máquina, natureza e cultura, vida e morte.

O conceito que hoje é conhecido como morte cerebral foi definido em 1959 na França. Até 1959 a comunidade médica reconhecia três tipos de coma: o coma vigile, coma type e o coma carus, que vão da menor intensidade (quando, por exemplo, o paciente perde apenas parte da vida de relação, mantendo mínima consciência e resposta motora) até o mais intenso (quando o paciente mantem apenas parte das funções vegetativas). Entretanto, dois neurologistas franceses, Mollaret e Goulon, analisaram eletroencefalogramas e dados clínicos de vinte e três pacientes em coma e concluíram que existe um tipo de coma, o coma dépassé, no qual há a abolição total da vida de relação e da vida vegetativa que ocorre, na maioria dos casos, segundo os autores, em decorrência do insucesso da reanimação respiratória (Mollaret e Goulon, 1959). No entanto, a publicação de Mollaret e Goulon não causou um grande impacto na comunidade médica e científica. Foi apenas em 1967, com a realização do primeiro transplante cardíaco, que o meio médico passou a se preocupar em definir um novo critério de morte. A realização do primeiro transplante de coração provocou uma euforia no meio médico, pois, mostrava que esse tipo de intervenção era possível de ser realizada e, ao mesmo tempo, um certo desconforto para a opinião pública e para magistrados que não reconheciam a morte do cérebro como morte (Lock, 2000). Assim, tornou-se imperativo que fosse formulado um novo conceito de morte que permitisse a realização de doação de órgãos. Nesse sentido, a publicação mais reconhecida é o Relatório do Comitê Ad Hoc da Escola de Medicina de Harvard (The Journal of the American Association, 1968), publicado em 1968 (que não cita o trabalho de Mollaret e Goulon). Este Relatório definiu os critérios de diagnóstico de morte encefálica como sendo: a não resposta a estímulos externos (estimulação da dor, toque, som ou luz); nenhum movimento muscular ou reflexos; incapacidade respiratória; e o resultado do eletroencefalograma, que deve 
ser plano (ou seja, sem corrente elétrica) (1968). De acordo com a Comissão organizada para definir este conceito, o coma irreversível (depois definido como morte cerebral nos Estados Unidos e como morte encefálica no Brasil) é um novo critério para definição de morte e a importância em definí-lo deve-se a duas razões:

(1) melhorias nas medidas de ressuscitação e suporte têm conduzido ao aumento de esforços para salvar aqueles [pacientes] que estão em estado grave. Às vezes, esses esforços têm apenas sucesso parcial, tanto que o resultado é um indivíduo cujo coração permanece batendo, mas cujo cérebro está com dano irreversível. O fardo é grande para os pacientes que sofrem perda permanente de intelecto, para seus familiares, para os hospitais e para aqueles que precisam de leitos hospitalares já ocupados por pacientes em coma (1968: 677, minha tradução).

É ainda importante destacar que, além de perder a capacidade de “vida vegetativa” (respiração, reflexos e movimentos), o paciente ${ }^{2}$ também apresenta a abolição total da vida de relação, ou seja, ele não pode mais estabelecer nenhum tipo de relação com as pessoas à sua volta, não tem mais consciência, desejos ou vontade. Na morte encefálica, por mais que se mantenham os sinais vitais através de equipamentos, a falta de consciência é considerada irreversível e, neste caso, está se considerando enquanto morte a falta de capacidade de raciocínio, consciência, desejo, ou seja, o paciente não seria mais uma "pessoa", conforme a definição de Dumont (1985) para o termo.

A partir dessa publicação se estabelece uma nova causa de morte, a morte do cérebro. O que não estava totalmente definido era à qual parte do cérebro o conceito se referia. Essa é uma discussão que perdura ainda hoje, já que existem três definições para morte do tecido cerebral. Assim, Lima (2005) explica que o conceito de morte encefálica propõe que o processo de morte encerra-se com a parada irreversível de todo o organismo (respiração, temperatura, consciência, equilíbrio hidroeletrônico, regulação hormonal), utilizando como critério de diagnóstico o cessar do funcionamento de todo o encéfalo, sendo que esse diagnóstico seria realizado por meio de testes que comprovassem a ausência de batimentos cardíacos, respiração e funções cerebrais. Contudo, os adeptos dos demais conceitos afirmam que em 40\% dos casos de morte encefálica é verificada alguma atividade elétrica no cérebro, assim como a presença de funções neuroendócrinas (Lima, 2005).

Outro conceito bastante difundido é o de morte do tronco cerebral, sendo adotado, primeiramente, pela União Soviética (1971), Reino Unido (1976), Estados Unidos (1968), 


\section{JULIANA LOPES DE MACEDO. AS REGRAS DO JOGO DA MORTE ENCEFÁLICA}

Portugal (1993) e Brasil (1996). Considera-se que o tronco cerebral é a parte específica do encéfalo responsável por coordenar as funções básicas, tais como: respiração, deglutição e sono. Conceitualmente, com a adoção desse critério, a morte passa a ser definida como a perda irreversível da consciência e da capacidade respiratória ocasionando, inevitavelmente, a parada do coração ${ }^{3}$. Para determinar a parada do tronco-cerebral recomenda-se a verificação de ausência de reflexos do tronco cerebral e o teste de apnéia. As críticas que este conceito recebeu baseiam-se na questão da ausência de respiração, já que adeptos de outros conceitos consideram que o estimulo à respiração é o que falta (fato que pode ocorrer em doentes vivos e conscientes) e a parada cardíaca nem sempre é observada.

Há ainda outro conceito - que por ser tão controverso não é considerado para verificação de morte -, o de morte cortical, que significa a perda de consciência e cognição e a perda da capacidade de interação social. De acordo com Lima (2005) o problema desse conceito é localizar a consciência para verificar seu não-funcionamento, além do fato de considerar como mortos pacientes em coma, ou em estado catatônico, por exemplo.

As questões apresentadas até o momento demonstram tanto o contexto no qual o conceito de morte encefálica surge, como as discussões médicas para definição do conceito e revelam o caráter ambíguo da morte encefálica. A ambiguidade em torno da morte encefálica foi, justamente, o que motivou o desenvolvimento da pesquisa que será apresentada ao longo deste artigo e, também, impôs o desafio de refletir sobre como o "ser" em morte encefálica deveria ser denominado ao longo da escrita. Durante o campo, percebi que, assim como na bibliografia sobre o tema, meus informantes ora faziam referência ao "paciente", "paciente em morte encefálica” ou "pessoa”; ora se referiam ao "morto", “cadáver", “doador”. Então, me deparei com o dilema de como tratar esse "ser". Se adotasse as palavras "paciente" ou "pessoa" estaria assumindo que esse "ser" não está (totalmente) morto. Porém, se utilizasse as palavras "morto" ou "cadáver" estaria assumindo que não há mais vida nenhuma nesse "ser". Uma primeira opção para garantir a neutralidade na escrita foi adotar o termo "doador" ou "possível doador", porém, a palavra, no decorrer da escrita, se mostrou limitada, visto que existem "possíveis doadores" que não serão tratados como tais pelos informantes. Numa tentativa de resolver o problema, de nominar o inominável, decidi adotar o conceito de cadáver-vivo de Margaret Lock (2000, 2002). Além da definição se encaixar à imagem do “ser" em morte encefálica, o termo me parece o mais neutro a ser utilizado, já que ele não pressupõe o status de vivo nem o de morto a esse "ser", pelo contrário, remete à ideia de meio-termo, de ambiguidade e de contradição. 
Antes de apresentar os dados da pesquisa, é preciso abordar outro aspecto que merece destaque no que diz respeito à morte encefálica: a importância que o conceito de morte encefálica assume para a doação de órgãos. Antes da definição do conceito de morte encefálica, em 1968, já eram realizadas cirurgias de transplantes de órgãos, como mencionei antes, com a utilização de doadores cadáveres (mortos por parada cardíaca) ou com doadores vivos. Atualmente, a principal fonte de obtenção de órgãos para transplantes é o doador cadáver com diagnóstico de morte encefálica (não é permitido no Brasil outro tipo de doador morto). A doação entre vivos é permitida, mas segundo meus informantes, extremamente limitada. E não é limitada por não haver doadores vivos dispostos a doar, mas porque os médicos não aconselham esse tipo de doação, pois, se trata de um "risco duplo" - tanto o receptor como o doador correm risco de morrer durante a cirurgia. Então seria trocar uma vida pela outra. Além disso, o doador nunca poderá voltar a ter uma vida completamente normal, conforme indicou Adolfo, cirurgião, membro de uma equipe transplantadora). As estatísticas também mostram que a maior parte dos órgãos utilizados em transplantes (exceto para transplantes renais) é de cadáveres em morte encefálica. No ano de 2006, por exemplo, foram realizadas no Brasil 1193 cirurgias de transplantes de órgãos (coração, fígado, intestino, pâncreas, pâncreas-rim e pulmão) com a utilização de doador cadáver, contra 194 transplantes com a utilização de doador vivo (Associação Brasileira de Transplantes de Órgãos, 2006). Esses dados demonstram a importância que este conceito e o seu diagnóstico assume para a questão dos transplantes de órgãos. Apesar de existir outras maneiras de se obter órgãos para transplantes, são os órgãos de doados através da morte encefálica que tornam as cirurgias de transplantes uma rotina médica.

Em face de tal importância e considerando que do ponto de vista teórico não há consenso sobre morte encefálica (visto que há três diferentes maneiras de diagnosticála), resolvi ir à campo para entender como que é estabelecido esse diagnóstico na prática. Pretendo demonstrar neste artigo que se trata de um processo constituído por várias etapas, no qual cada uma definirá a próxima. É como se fosse um jogo de tabuleiro em que a sorte define quantas casas serão avançadas ou retrocedidas. Se o jogador conseguir avançar as casas, encontrará no final do jogo as cirurgias de transplantes de órgãos. Nesse sentido, o presente artigo analisa a maneira como é operacionalizado o conceito de morte encefálica entre médicos, a partir do processo de diagnóstico desta morte. 


\section{Procedimentos Metodológicos}

A fim de compreender as concepções de morte encefálica entre médicos, privilegiei como técnica de coleta de dados a entrevista não-diretiva que tem como proposta principal permitir que o indivíduo entrevistado fale da forma mais livre possível sobre um determinado tema. Esta técnica minimiza as possíveis distorções produzidas pelo entrevistador, comparada ao questionário fechado e, ainda, possibilita a obtenção de respostas mais profundas dos indivíduos entrevistados (Kandel, 1987). Sendo assim, foram realizadas onze entrevistas entre médicos, que tiveram como proposta discutir com os entrevistados uma série de questões a respeito da trajetória profissional, além do tema da morte e, mais especificamente, da morte encefálica. Todas as entrevistas foram gravadas e realizadas nos hospitais nos quais os informantes trabalhavam, na cidade de Porto Alegre/RS.

Os atores sociais escolhidos para fazer parte deste estudo foram os médicos que possuem maior envolvimento com o tema da morte encefálica, ou seja: médicos que atuam em Unidades de Terapia Intensiva (UTI) e médicos que fazem parte de equipes de transplantes. O estudo poderia abarcar outros atores sociais que também estão imbricados na situação de morte encefálica, como por exemplo, familiares de pacientes que tiveram este diagnóstico. Contudo, estou considerando a morte encefálica enquanto um conceito (técnico e científico) e, portanto, o foco da pesquisa foi os atores sociais responsáveis pela operacionalização deste conceito.

\section{Iniciando o Jogo - a operacionalização do conceito}

De acordo com os médicos intensivistas entrevistados, existem duas causas principais para morte encefálica: acidente vascular-cerebral (AVC, ou o popular "derrame”) e traumatismos cranianos $^{4}$. O paciente que tem suspeita de morte encefálica encontra-se em coma, assim, há duas possibilidades para a suspeita se transformar em confirmação: (1) em UTIs, onde estão presentes alguns médicos mais sensíveis sobre o tema (como no caso de uma UTI de um dos hospitais pesquisados, onde um dos médicos entrevistados faz parte de uma equipe intra-hospitalar de transplantes ${ }^{5}$, os médicos assistentes realizam os testes clínicos para a primeira confirmação da morte encefálica; (2) mas o que acontece geralmente, nas demais UTIS, é algum membro da equipe intra-hospitalar de transplantes visitar as UTIs e verificar se algum paciente poderia estar nesta situação. Isto é afirmado, por exemplo, pelo chefe de uma das UTIS onde realizei campo: "É um componente da equipe intra-hospitalar de transplantes 
que vai até às UTIs verificar se há pacientes que podem estar em morte encefálica” (Rafael, médico chefe de uma UTI).

Parece haver uma "caça aos mortos" por parte daqueles profissionais mais envolvidos com a questão dos transplantes. Caso se suspeite de que algum paciente esteja em morte encefálica, o membro da equipe intra-hospitalar de transplantes solicita ao médico responsável pelo paciente a realização dos exames. Os intensivistas comentam que alguns colegas, por concepções morais, se negam a fazer os exames. As concepções morais referidas pelos informantes que fazem com que alguns médicos se recusem a participar do diagnóstico não dizem respeito a moral religiosa, tendo em vista que a maior parte das religiões é favorável à doação de órgãos. O que os médicos querem dizer com "impedimentos morais" para atestar a morte encefálica diz respeito à moral do próprio campo médico que assume como vocação a manutenção da vida. Nesse sentido, apesar da morte encefálica ser um conceito legitimado pelo campo médico, para alguns médicos, a vida ainda está associada ao funcionamento do coração e, portanto, atestar morte encefálica poderia ser o equivalente a atentar contra a vida. Nenhum médico é "obrigado" a realizar os procedimentos, mas a instituição (no caso, a UTI), diante de uma suspeita (e da pressão da equipe intra-hospitalar de transplantes), o é. Assim alguém terá de fazê-lo. A pressão exercida pela equipe intra-hospitalar de transplantes para a execução dos exames diagnósticos evidencia que o conceito de morte encefálica não foi introduzido na prática médica dos intensivistas (justamente aqueles que deveriam se encarregar de operacionalizá-la). Ao mesmo tempo, esta situação revela a desconfiança dos responsáveis pela captação de órgãos sobre a não realização dos testes pelos intensivistas.

O primeiro exame clínico consiste em realizar testes de reflexos e o teste de apnéia (retirar o ventilador mecânico para verificar se o paciente tem capacidade para respirar sozinho). Estes exames são realizados por um intensivista que não pode estar vinculado à equipe intra-hospitalar de transplantes do hospital no qual se encontra o paciente em suspeita de morte encefálica, nem pode estar associado a nenhuma equipe de transplante de órgãos de nenhum hospital. Um dos intensivistas entrevistados afirma que durante um ano aceitou estar vinculado a uma equipe de transplantes para não ter que se envolver no diagnóstico de morte encefálica. De acordo com ele, "Existem médicos que se recusam a fazer exames de comprovação de morte cerebral porque não concordam moralmente com isso. Eu não chego a tanto, mas eu não me sinto muito à vontade quando tem paciente em morte cerebral e eu tenho que assinar os exames" (Daniel, médico plantonista de uma UTI).

Na tentativa de evitar conflitos de interesses, para o Sistema Nacional de Transplantes 


\section{JULIANA LOPES DE MACEDO. AS REGRAS DO JOGO DA MORTE ENCEFÁLICA}

é imperativo que os participantes de cada fase da doação de órgãos (diagnóstico, negociação da doação junto à família e transplante) não participem das demais, buscando, desta forma, que o processo seja neutro e imparcial. Mas esta prerrogativa pode ser utilizada por alguns médicos para escapar da responsabilidade de dar o diagnóstico de morte encefálica. É o que demonstra este informante que, sabendo da impossibilidade de realizar diagnóstico de morte encefálica, e, ao mesmo tempo, estar em uma equipe de transplantes, optou pela participação na etapa dos transplantes para não ter que realizar o diagnóstico, pois não se sente à vontade com a situação.

Outros médicos também comentaram que existem colegas que se negam a realizar os exames, o que é aceito pela equipe da UTI, pois todos entendem que este não é um conceito de fácil compreensão. Neste caso, a equipe intra-hospitalar de transplantes procura na própria UTI outro médico que aceite realizar os exames. Além de impedimentos morais e de desconfiança frente ao conceito de morte encefálica, há o medo de um possível erro de diagnóstico - erro que declararia um vivo como um morto (Lock, 2000, 2002).

Se houver a primeira confirmação de morte encefálica, o médico assistente comunica à família que existe a possibilidade de o "paciente" estar em morte encefálica e que serão realizados mais exames para comprovar o diagnóstico. Ainda que a equipe tenha certeza que está diante de um caso de morte encefálica, a notícia é dada para a família aos poucos, assim, num primeiro momento, por mais que os médicos estejam tentando preparar a família para “o pior”, é possível que esta ainda tenha alguma esperança de que o diagnóstico não seja comprovado. Então, com a primeira confirmação, se avança uma casa no jogo; se não houver confirmação, o jogo acabou.

\section{A Segunda Etapa: a contraprova da morte encefálica}

Transcorridas seis horas da primeira bateria de exames, um neurologista é convocado para a repetição dos mesmos testes. Isso serve para minimizar a possibilidade de erro, pois, são dois profissionais diferentes analisando o mesmo caso. Além disto, a presença do neurologista se faz necessária, porque esta é a especialidade que detém o monopólio sobre o conhecimento do cérebro. Desse modo, se o neurologista chamado para a realização dos testes confirmatórios discordar do primeiro, o processo de diagnóstico de morte encefálica é interrompido, o jogo termina, e o cadáver-vivo permanece em "tratamento", conforme explicarei melhor a seguir. Se 
JULIANA LOPES DE MACEDO. AS REGRAS DO JOGO DA MORTE ENCEFÁLICA

houver a comprovação, avança-se mais uma casa, e o médico intensivista comunica à família a confirmação do diagnóstico e informa que outro teste, agora um exame de imagem, será realizado para a confirmação final. Hoje, o teste mais recomendado para este diagnóstico é a arteriografia, que oferece uma imagem das artérias do cérebro ${ }^{6}$. O exame consiste em se injetar um contraste nessas artérias para verificar o movimento do líquido, ou seja, se houver atividade cerebral, é possível ver o contraste subindo pelas artérias até o cérebro. Se não houver atividade cerebral, o contraste não chegará até o cérebro e isto indicará que o fluxo sanguíneo do cérebro foi interrompido.

Portanto, se o exame de imagem demonstrar que não há atividade cerebral, se avança mais uma etapa no jogo, e o médico intensivista comunicará a morte para a família e notificará para a Central de Transplantes do Estado a existência de um possível doador. É também interessante o uso de um exame de imagem, pois esta torna, aparentemente, o diagnóstico mais objetivo, pois se vê, e não apenas se deduz. Com a comprovação visual (feita por uma máquina) busca-se minimizar as chances de erros de um diagnóstico baseado na percepção do médico em relação ao exame clínico e ao teste de apnéia. Se por um lado as imagens que esses equipamentos produzem não estão isentas de interpretações, afinal, precisam de um mediador (o médico) para fazer sua tradução, por outro lado, é bastante reconhecido o poder que estas imagens possuem enquanto fatos visuais em diversas arenas da vida social, como a comunidade médica, científica, jurídica e a mídia (Dumit, 2003).

\section{A Terceira Etapa - negociando a doação}

Até este momento, o cadáver-vivo dessegue sendo um "possível doador", porque ele só será efetivado como doador se houver a concordância da família para a doação e se o "possível doador" não tiver nenhum impedimento clínico para a realização da doação - como alguma doença infecciosa que possa ser transmitida ao receptor. A interação do médico intensivista com a família termina com a notícia da morte, ficando a tarefa de solicitar aos familiares a doação dos órgãos a cargo da equipe intra-hospitalar de transplantes.

Com relação à comunicação da morte encefálica do cadáver-vivo para a família, em um primeiro momento, a maior parte dos intensivistas entrevistados acredita que, para o médico, esta situação é tão difícil quanto dar a notícia de qualquer doença ou situação irreversível. No entanto, todos os informantes chamam atenção para a dificuldade de aceitação desse 


\section{JULIANA LOPES DE MACEDO. AS REGRAS DO JOGO DA MORTE ENCEFÁLICA}

diagnóstico pela família. Segundo eles, essa dificuldade reside no fato de que ainda existe muita desconfiança a respeito desse diagnóstico para a população leiga, que está diante de um corpo quente que tem o coração batendo. De acordo com Clarissa, uma média intensisvista entrevistada, uma das dificuldades relacionada à aceitação do diagnóstico se deve ao contexto da morte, já que as vítimas de morte encefálica são, majoritariamente, pacientes muito jovens, que sofreram acidentes graves de uma maneira totalmente inesperada. Um dos informantes sintetiza esta questão da seguinte maneira:

O coração está batendo ainda. As pessoas... algumas já sabem, já ouviram falar, mas a grande maioria tem dificuldade em aceitar isso. E, geralmente, o evento é muito agudo, ele incide sobre gente saudável, geralmente jovem, e é normal que os familiares também neguem... a morte em si. Quanto mais uma morte meio técnica. Não é nem uma questão (às vezes o pessoal coloca: “são questões religiosas!”), não são questões propriamente religiosas. São questões talvez antropológicas, de aceitação de um conceito estranho para eles (Matheus, médico chefe de uma UTI).

Desta maneira, além de envolver as dificuldades inerentes à morte inesperada e de pessoas jovens, a morte encefálica não é um evento de fácil compreensão pelas pessoas, por fugir à ordem "natural" (ou pelo menos mais "tradicional") que prevê que enquanto o coração estiver batendo ainda há vida. Tanto a morte prematura como a morte causada por motivos que não são claros, como a encefálica, são fonte de desordem social e, como nos lembra Mary Douglas (1991), a desordem é fonte de insegurança e perigo, por isso é quase inevitável o desconforto diante deste diagnóstico.

Quando solicitei aos meus informantes uma definição para morte, seis dos sete transplantadores entrevistados definiram morte enquanto morte encefálica, porque eles entendem que o cérebro é o órgão central na articulação dos demais sistemas biológicos do corpo e, assim, o não-funcionamento do cérebro levará à parada de todos os demais órgãos. Além disso, eles julgam que, ao contrário da parada cardíaca, a morte encefálica é invariavelmente irreversível. Entretanto, como expus antes, o mesmo não ocorre entre os intensivistas, que, em sua maioria, não percebem morte encefálica como morte natural. Os intensivistas apresentaram um leque maior de opções para definir morte. Assim, enquanto para dois intensivistas a morte é o equivalente à morte encefálica, para outros ela pode ser definida como a cessação de toda e qualquer atividade biológica (o que não se aplicaria à morte encefálica), a parada cardíaca (considerada como a morte natural) e a perda da autonomia, da 
vontade e da personalidade. A questão da autonomia do indivíduo foi bastante importante para definir vida e morte: “Se eu tivesse uma sequela muito grave - não morte cerebral... mas um estado vegetativo persistente, muito significativo - eu me consideraria morto, e gostaria que os meus familiares me considerassem assim" (Matheus, médico chefe de uma UTI).

Assim, para estar vivo precisar-se-ia ser uma pessoa, um ser dotado de individualidade, vontade própria, autonomia, alguém que não possui esses quesitos perde sua humanidade, passa a ser um corpo, um organismo biológico simplesmente; dessa maneira, teria vida da mesma forma que uma planta tem, mas não teria mais vida humana. No conjunto geral das entrevistas foi muito frequente ouvir que morte encefálica corresponde à morte, mas, não representa a morte biológica do corpo. A morte seria então o fim da pessoa, do ser consciente, dotado de razão, vontade e ação. Segundo Dumont (1985), o indivíduo é a noção de pessoa para a sociedade ocidental, e independência, autonomia e racionalidade são critério fundamentais para defini-lo. A morte corresponderia, então, à “não-pessoa”, e como as características necessárias para uma pessoa ser considerada uma "pessoa viva" são reguladas pelo cérebro, a morte cerebral representaria o fim da pessoa, mas, conceitualmente, isso também poderia ser estendido para qualquer outro dano cerebral que torne a pessoa inconsciente e incapaz de expressar a sua racionalidade, como pacientes em coma ou em estado vegetativo (como o próprio informante se referiu), mas, que não poderia ser considerado morto pelos cânones da medicina.

Chama atenção que, mesmo sendo considerada a maneira legítima para definir morte, a morte encefálica é concebida pelos intensivistas como uma morte "não-natural" e pelos médicos de equipes de transplantes como uma "morte técnica", fato que é explicitado na seguinte fala:

Eu sou muito técnica nas minhas avaliações, e acho que morte - até para quem trabalha com transplante - tem que estar ligada à perda de controle cerebral; uma das funções básicas, então. Eu trabalho muito com o conceito de morte encefálica para definir o que é que é morte para mim; senão até fica complicado eu trabalhar com transplante e não estender isso para o meu diaa-dia (Roberta, clínica, membro de uma equipe de transplante).

Esta fala é exemplar para compreender algo que perpassa as demais entrevistas entre médicos transplantadores, ou seja, revela que a importância da morte encefálica está relacionada à prática profissional dos informantes, já que um médico que trabalha em uma equipe de transplantes precisa acreditar no conceito de morte encefálica para realizar o seu 


\section{JULIANA LOPES DE MACEDO. AS REGRAS DO JOGO DA MORTE ENCEFÁLICA}

trabalho. Chama atenção também a ênfase dada à "morte técnica", demonstrando uma certa ambiguidade sobre a morte encefálica. Em outras palavras: na prática profissional, a morte encefálica é um bom conceito para definir morte, e, além disso, é necessária para se trabalhar em uma equipe transplantadora, mas, para a vida pessoal, nem tanto. Exemplo disto é que quando perguntada sobre qual é a hora da morte que consta no atestado de óbito do doador (se seria o momento da constatação de morte encefálica ou o momento da remoção do coração), essa informante afirma, sem titubear, que é o momento da retirada do coração. É interessante notar a importância que ainda é atribuída ao coração. Tanto médicos transplantadores como intensivistas afirmaram que a hora do óbito "de fato" é o momento da parada cardíaca, essa seria a morte definitiva e natural, opondo-se, como eles mesmos dizem, à "morte técnica", que seria a morte encefálica.

O caráter técnico da morte encefálica está também presente no discurso dos intensivistas, no entanto, com um enfoque diferenciado daquele apresentado pelos transplantadores. Esta ideia é apresentada pelos intensivistas, principalmente quando é narrado o surgimento do conceito de morte encefálica. Alguns intensivistas entrevistados acreditam que a morte encefálica seria fruto da própria uTI e do desenvolvimento tecnológico atrelado a ela. Eles defendem que a possibilidade de conceituação desse tipo de morte foi criada com o advento da ventilação mecânica, o que permitiu também a criação da própria UTI. Outra questão abordada apenas pelos intensivistas foi a variação dos conceitos e concepções acerca da morte encefálica, variações que eles denominam como "culturais". Dessa forma, eles argumentam que da mesma forma que os critérios utilizados para a definição conceitual e diagnóstico de morte encefálica não são os mesmos em todos os países, também não são todos os países que aceitam esse diagnóstico para determinar a morte do indivíduo. Uma das intensivistas entrevistadas afirma que, em alguns países, aceita-se a definição de morte do córtex, ou seja, a pessoa estaria morta se não houvesse consciência, mesmo que estivesse respirando sozinha. Ao mesmo tempo, em outros países, mesmo a noção de morte cerebral não é aceita.

Lock (2002) afirma que na medicina existe uma espécie de economia moral que determina a conduta médica e que transcende as fronteiras geográficas e culturais. Dessa maneira, se a prática médica é universal, então as concepções de morte encefálica deveriam ser uniformes, pelo menos do ponto de vista oficial. Porém, se em caráter oficial existem essas variações, sugiro que a morte encefálica está baseada em concepções que vão além das "científicas", pois, no final das contas, estamos falando sobre morte, tema que não 
pertence a um único domínio do conhecimento e que perpassa, mesmo que de forma não nomeada, todos os domínios da vida social. Quero chamar atenção aqui para a contestação da morte encefálica enquanto um critério bem definido, definitivo e indubitável. Se existem variações "culturais", se os critérios adotados não são os mesmos entre diferentes países, como manter a irrefutabilidade da morte encefálica? É interessante enfatizar que esta questão só foi abordada pelos intensivistas, justamente os médicos que adotam uma postura mais crítica frente ao conceito de morte encefálica; nenhum médico pertencente a equipes de transplantes fez referência a estas variações teóricas do conceito de morte encefálica.

Uma série de outras ambiguidades envolve a morte encefálica, além de se tratar de uma morte técnica, ou seja, construída a partir de conceitos teóricos e de não haver um momento exato para definí-la (suspeita-se de que o paciente esteja nessa condição e, então, iniciam-se os procedimentos para sua comprovação). Uma destas ambiguidades está no fato de que, embora a morte encefálica represente o mesmo que morte, não significa a morte do corpo, como pode ser percebido na fala a seguir:

Bom, antigamente se achava que morria quando parava o coração. Mas como o coração pera hoje em dia e a pessoa não morre, então as coisas mudaram. $\mathrm{Na}$ verdade, eu aceito o conceito de morte cerebral, ou seja, o cérebro não tem mais circulação e, portanto, não tem mais retorno, e ele nunca mais funcionará. (...) Mas o corpo não morre junto. Morreu o cérebro, daí depois começam a morrer outros tecidos - tem tecidos que levam horas para morrer, que resistem (Adolfo, cirurgião, membro de uma equipe de transplante).

Lock $(2000$, 2002) também comenta que, entre os médicos americanos entrevistados por ela, a ideia de que a morte encefálica, por mais que seja uma condição aceita e irreversível, não significa a morte biológica do corpo. Isso oferece a este tipo de morte um caráter ambíguo. Um dos meus informantes conta uma história muito interessante vivenciada por ele durante a primeira cirurgia de remoção de órgãos de doador falecido que ele realizou, que é um bom exemplo para pensar a respeito da ambiguidade do status de morte encefálica, na qual a pessoa não está nem viva nem morta e, na dificuldade que mesmo os profissionais da área da saúde têm para aceitar essa forma de morrer:

... da primeira vez que aconteceu conosco aqui foi um Deus nos acuda! A gente não conhecia muito (isso foi vinte anos atrás), não conhecia muito essa fisiologia do cadáver que está respirando... E eu, quando coloquei o bisturi, para abrir de cima a baixo... O paciente, o morto... trouxe as mãos na minha direção. Aí, 
imediatamente, a enfermagem da sala se recusou, saiu e não quis mais continuar: "nós não vamos participar disso aî". Por mais que eu explicasse, diziam "não, nós não queremos". Eu não posso obrigar. Daí eu consegui outras pessoas, entende? Aí tem a minha equipe, aí quem instrumentou foi um doutorando de Medicina, os residentes ajudaram, e a circulante foi um dos nossos que circulou na sala. E eu respeitei também o sentimento dos funcionários, que também não são profissionais do assunto, e não conhecem isso, não é? Mas, tu que já viste uma lagartixa cortar a cabeça e sair pulando, tu sabes que ela não tem cabeça! Então nós tínhamos segurança de que era assim, mas realmente causa comoção; até eu me arrepiei um pouco, mas eu conheço o assunto. A partir daí nós passamos a anestesiar o cadáver. Parece um absurdo, mas, nós anestesiamos - para evitar esses movimentos maiores, que são involuntários... (Adolfo, cirurgião, membro de uma equipe de transplante).

Um “cadáver que está respirando" e, além disto, que se mexe, como ele mesmo comenta, é um fato que "causa comoção". Até o cirurgião, alguém que "conhece o assunto", se "arrepiou um pouco" e, apesar de parecer "um absurdo", a partir deste evento se passou a anestesiar o cadáver. Todos os elementos que ressaltei desta fala demonstram a ambiguidade do "ser" que se encontra em morte encefálica, um híbrido, um morto em um corpo vivo, a conjunção da máquina e do organismo biológico - conjugação que é pré-requisto para a existência da morte encefálica.

Outro aspecto por meio do qual é possível perceber as contradições da morte encefálica é o entendimento que os médicos entrevistados têm sobre a "hora da morte" que deve ser registrada no atestado de óbito, ou seja, se o momento em que a morte deve ser decretada oficialmente seria quando se tem a comprovação do diagnóstico de morte encefálica ou se seria no momento em que o coração foi removido, em caso de doadores. Podemos notar que não houve consenso entre as respostas dadas, como exponho a seguir:

Boa pergunta. (...) Eu acho que é a hora da retirada. (...) Até porque, assim... Não, é a hora da retirada, mesmo. Porque, até então, ele tem o prontuário, ele é um paciente ainda. Aí, quando a gente tira o coração, o anestesista desliga as coisas dele, e aí sempre o pessoal diz “ó, tal hora” e tal. Então é nesse momento (Vitória, cirurgiã, membro de uma equipe de transplante).

Não sei... Não! Mas já sei: é na morte encefálica. No momento da morte encefálica já é feito. Nós só operamos com o atestado de óbito pronto. Nós operamos cadáveres. Então no momento em que atestou a cintilografia 
morte cerebral, o médico então atesta e dão atestado de óbito. E vem o cadáver com o atestado de óbito, mas ele está respirando, com aparelho. Então aí nós só desligamos, não importa essa hora qual seja, a gente tem que fazer isso para entregar para a família depois o que restou - hoje em dia se tira muita coisa, não é? (Adolfo, cirurgião, membro de uma equipe de transplante).

Em primeiro lugar, chama atenção a insegurança inicial nas duas falas para responder à pergunta. Em segundo lugar, mesmo tendo titubeado no início, ambos informantes oferecem detalhes para justificar a resposta: “tem prontuário", por isso "ainda é paciente”, ou então, “nós operamos cadáveres". Diante destas duas respostas contraditórias não me interessa saber qual é a opção correta, mas chamar a atenção que, embora os transplantadores fossem muito seguros quando diziam que a morte corresponde à morte encefálica, esses detalhes revelam os descompassos que me fazem pensar que a morte encefálica não é um conceito tão preciso como a medicina tem proposto.

Outra questão bastante comentada entre os intensivistas foi a desconfiança por parte das famílias de que o cadáver-vivo não esteja morto realmente. Nas palavras deste informante:

Mas quando se dá a notícia de morte cerebral, 50\% das famílias ainda desconfiam que isso não deva ser verdade, mas, quando uma pessoa morre de outra causa, raramente há esse tipo de desconfiança. (...) Pra notícia de morte cerebral o convencimento é complicado pra boa parte das pessoas. (...) Existe uma fé, dada pelas revistas, pelos programas de televisão, pela própria onipotência médica que nós em uTI fazemos milagres, então criamos um monstro entre aspas, uma expectativa de sucesso que não pode ser concretizada na maior parte das vezes. E nesse sentido, dizer que não há mais nada pra fazer é muito complicado, as pessoas acreditam nisso porque é vendido isso pra elas (Daniel, médico plantonista de uma UTI).

A questão da não confiança no diagnóstico de morte encefálica envolve questões que vão além da dificuldade de conceber como morto alguém que tenha o coração batendo. Somase a isto a decepção com a morte de alguém que estava no único lugar que tinha todos os recursos para "salvar vidas". Em sua etnografia sobre um Centro de Tratamento Intensivo, Menezes constata que: "O СТі pode ser considerado um local onde a tensão estruturante da Medicina - o "cuidado" e a "competência" - apresenta-se de forma particularmente explícita, tendo em vista a importância da tecnologia nesse setor” (2001: 118). 


\section{JULIANA LOPES DE MACEDO. AS REGRAS DO JOGO DA MORTE ENCEFÁLICA}

Além da tecnologia, a autora também chama atenção para importância dada à competência técnica pelos profissionais que atuam em CTIs, competência que é constantemente reafirmada por eles frente a outros profissionais do hospital. Dessa maneira, a morte em um local no qual estão presentes os melhores profissionais e as mais sofisticadas tecnologias é sempre uma derrota (Menezes, 2001).

Outros informantes também indicaram que as famílias temem que o cadáver-vivo seja dado como morto sem que isto seja verdade, com o objetivo de desocupar o leito, ou de remover seus órgãos “a qualquer custo”, ou seja, mesmo sem a confirmação da morte. Estas ideias são alimentadas pelas recorrentes notícias veiculadas nos meios de comunicação a respeito da precariedade do Sistema Único de Saúde e de processos envolvendo erros médicos e corrupção. Posso citar, como exemplo, uma pesquisa realizada por Rodrigues e Sato em um Hospital de São Paulo sobre doação e atitudes da população sobre transplantes de córneas. Dentre as pessoas que se manifestaram como não doadoras, 53\% justificavam essa posição devido ao "medo e insegurança quanto ao destino do órgão doado e dúvidas quanto a possível negligência de tratamento pelo fato de ser doador" (grifos do original, apud Shikida e Araújo Jr., 2004: 19). Lock (2000, 2002) também afirma que ainda se tem medo sobre o pronunciamento prematuro da morte, pois as decisões sobre cuidados clínicos de pacientes terminais sempre envolvem julgamentos morais.

Ainda com relação aos motivos da negação de doação de órgãos, Scheper-Hughes e Biehl (2000), após demonstrarem vários indícios de casos de tráfico de órgãos (de “doadores” vivos e cadáveres) em países do terceiro mundo, concluem que estes boatos criam uma "resistência civil" com relação à doação de órgãos, mesmo quando esta situação ocorre em um contexto legal. Desta maneira, não serão uma política pública a favor da doação de órgãos, ou as justificativas dadas pela ciência para legitimar a morte encefálica que influenciarão as decisões de doação de órgãos, mas sim as concepções mais gerais que os indivíduos têm sobre o mundo em que vivem.

Além dos elementos já citados, outro fator que pode contribuir para a desconfiança sobre o diagnóstico de morte encefálica é a sua vinculação com os transplantes. Ao estabelecer a vinculação entre morte encefálica e transplantes, cria-se a impressão de que o conceito de morte encefálica só existe em função da necessidade de se obter órgãos para transplantes. Segundo um intensivista, a morte encefálica envolve um:

...contexto de prioridades que transcende o indivíduo daquele corpo, é uma interferência da comunidade na atividade individual. $\mathrm{Na}$ verdade, como se 
definiu que pessoas poderiam sobreviver com sua atividade mental, cognitiva e de desejo, e a pessoa em morte cerebral já não pode fazer isso, a sociedade se organizou - a sociedade científica se organizou - pra considerar que pessoas nesse estado de incapacidade de expressar qualquer intenção ou desejo fossem úteis a outras (Daniel, médico plantonista de uma UTI).

A ideia de que a morte encefálica nasce em um "contexto utilitário" no qual a "sociedade científica" definiu que determinadas pessoas poderiam servir como doadoras de órgãos, somada à percepção de que não existe apenas uma forma de definir a morte encefálica, já que o conceito muda de acordo com o contexto cultural, enfraquece a legitimidade do conceito de morte encefálica na perspectiva dos intensivistas. Apesar de ter legitimado oficialmente esta nova forma de morrer, na prática, questões como o "caráter utilitário", a precariedade dos serviços públicos de saúde e a corrupção que obscurecem o conceito de morte encefálica provocam dúvidas e inseguranças sobre a veracidade deste conceito e contribuem, dessa maneira, para a negação de doação de órgãos.

\section{A Quarta Etapa: a transformação de paciente para doador}

Com o diagnóstico de morte encefálica oficializado, há duas possibilidades: efetivar a doação ou não. Se o cadáver-vivo tornar-se um doador de órgãos, a Central de Transplantes do Estado será acionada e o processo de doação terá início. Se o cadáver-vivo não for, por qualquer motivo, um doador, começam os problemas e o jogo termina. Um dos dados obtidos entre os intensivistas que mais me chamou atenção diz respeito aos procedimentos adotados nas UTIS quando a família nega a doação ou quando o "possível doador" tem algum impedimento clínico para a doação de órgãos, que é a impossibilidade de desligar os equipamentos que mantêm o cadáver-vivo "vivo". De acordo com meus informantes, morte encefálica equivale à morte, no entanto, isto só é verdade quando se trata de doação de órgãos, ao contrário, o cadáver-vivo permanece mantido ligado aos aparelhos até que seu coração pare de bater, pois, "não há amparo legal para desligar os equipamentos" (Jonas, médico chefe de uma UTI). Outro informante comenta que:

Não é desligado, continua em tratamento, porque a legislação não contempla esse tipo de conduta. A família espera pela morte natural, porque ela vai acontecer. A pergunta clássica nesse momento é "quanto tempo vai 
demorar?" e a resposta também é clássica: "a gente nunca sabe, pode ser daqui a uma hora, pode ser daqui a um dia, pode ser daqui a uma semana". Tem muitas variáveis aí: se o paciente é mais jovem, se tem outras complicações, se aconteceu isso por acidente, ou se foi por uma parada cardíaca (Rafael, médico chefe de uma UTI).

Bitencourt et al. (2007) verificaram em uma pesquisa realizada entre estudantes de medicina que, em casos de pacientes em morte encefálica e não doadores, apenas 66,4\% retirariam o suporte de vida. Os mesmos autores afirmam que em um estudo realizado na Polônia, verificou-se que $100 \%$ dos médicos entrevistados confiavam no diagnóstico de morte encefálica, porém, apenas $44 \%$ destes profissionais se diziam preparados para desligar os aparelhos que mantinham os corpos vivos. Após a realização das entrevistas, o Conselho Federal de Medicina publicou uma Resolução que autoriza os médicos a desligarem os equipamentos de suporte de vida em caso de não doação de órgãos (CFM, 2007). Poderia-se pensar que o problema agora está resolvido, mas se prestarmos atenção à frase "A família espera pela morte natural" citada pelo informante, notamos que o problema não se resolve com uma simples resolução (cabe enfatizar que, além disto, a resolução não possui força de lei).

A morte encefálica aparece no discurso dos informantes como um critério técnico e científico, enquanto que a parada cardíaca assume o papel de "morte natural", sendo considerada como a morte verdadeira, a mais apropriada e definitiva. Outro informante ainda afirma que:

Essa é a contradição. É uma contradição real porque se há uma autorização utilitária, por que não a utilidade daquele leito pra um terceiro que está esperando? Então fica na CTI, fica com os equipamentos, fica com o suporte, claro que em tese, não se acrescenta a esse paciente nada além, dificilmente vai se ficar dando mais medicação pra manter pressão, ou dando antibióticos, mas de qualquer maneira, até poderia ser questionado isso pelas famílias, "por que não dar o antibiótico? Nós não doamos os órgãos porque achamos que ele tem chances", então poderia questionar isso, eu acho legítimo questionar isso (Daniel, médico plantonista de uma UTI).

Esta fala sintetiza muitas questões envolvidas neste impasse. Por um lado, não se pode, efetivamente, desligar os equipamentos, porém, nenhum esforço é realizado para manter o cadáver-vivo com funções vitais estáveis. Os informantes são unânimes nesta questão e alguns vão além, e afirmam que em casos de necessidade de leitos na uTi ou de quantidade 
insuficiente de ventilador mecânico, se apressa a morte "natural" do cadáver-vivo ao se desligar os equipamentos. Contudo, os informantes que revelaram este fato ressaltam que o procedimento é feito da maneira mais discreta possível, por mais que os demais colegas saibam que isto é "normal" (e talvez também já tenham feito isto), ninguém comenta o que vai fazer, simplesmente faz.

Existe uma tênue fronteira entre a situação descrita pelos intensivistas e a eutanásia, o ato de provocar ativamente a morte de um paciente, visto que, se há o impedimento de desligar os equipamentos, então, o cadáver-vivo está sendo considerado como uma entidade viva. Mas, por outro lado, se técnica e cientificamente, este cadáver-vivo é considerado como um ente morto para a medicina, então, não há nenhum remorso em suspender o suporte de vida, até porque, desta forma, se abre a possibilidade de tratar outro paciente com chances de cura, que talvez não fosse atendido por falta de vaga na UTi. A perspectiva entre eutanásia e futilidade terapêutica ${ }^{7}$ - ou seja, se o intensivista está "matando" o cadáver-vivo ou se está retirando o suporte de vida de alguém que já está morto - vai depender da posição ocupada pelo agente no jogo e de suas concepções sobre vida e morte. É interessante mencionar também que uma das "promessas" da morte encefálica é a desocupação de leitos utilizados por pacientes “inviáveis", entretanto, na prática não é o que ocorre, pelo menos, não pelas vias oficiais.

As ambiguidades e incertezas relacionadas ao cadáver-vivo são percebidas, também, na forma discursiva utilizada pelos médicos entrevistados para se referir a ele. O status do cadáver-vivo provoca tantas dúvidas que é difícil até nominá-lo:

Nós mantemos a pessoa com pressão adequada, em boa situação física do corpo, para poder levar para a sala de cirurgia, abrir, retirar os órgãos todos (Adolfo, cirurgião, equipe de transplante renal).

Só que esse paciente que está teoricamente, teoricamente não, na prática, falecido... só que esse paciente que é falecido, e se ele é um potencial doador, ele tem que ser visto como um paciente com a mesma possibilidade de cura (Luiza, cirurgiã, equipe de transplante hepático).

Estas falas evidenciam uma confusão na maneira de classificar o cadáver-vivo. Ora ele é denominado como pessoa ou paciente, ora como falecido, ora como doador. Entretanto, quando se faz referência a uma pessoa ou a um paciente está se considerando que este tem vida, a partir do momento que não se é mais pessoa ou paciente passa-se a ser cadáver, falecido, morto ou doador. 


\section{JULIANA LOPES DE MACEDO. AS REGRAS DO JOGO DA MORTE ENCEFÁLICA}

A utilização de todos estes termos como se fossem sinônimos revela a dificuldade em se nominar o cadáver-vivo. É como se ele estivesse em um momento de liminariedade - como propõem Van Gennep (1978) e Turner (1974) ao estudarem ritos de passagem - na fronteira entre dois mundos distintos, na qual ele não é mais o que era antes do evento da morte encefálica (uma pessoa, um paciente), mas ainda não adquiriu o status de morto, cadáver, falecido, pois, o coração permanece em funcionamento.

A preposição "em" (em morte encefálica) reforça esta ideia, pois, se o cadáver-vivo em vez de morte encefálica tivesse tido uma parada cardíaca, não se diria que ele está "em parada cardíaca", e sim morto. O uso corrente da expressão em morte encefálica também não pode ser explicado pela falta de outros termos para se referir ao cadáver-vivo já que termos como paciente morto encefalicamente ou paciente cerebralmente morto poderiam substituir o termo usual. Mary Douglas ao comentar sobre liminariedade afirma que:

Examinamos as crenças relativas aos seres marginais, aqueles que, duma maneira ou de outra, são excluídos da ordem social, aqueles que não têm lugar. Mesmo que não possam ser repreendidos no plano moral, o seu estatuto é indefinível. Consideremos, por exemplo, a criança que ainda não nasceu. A sua situação presente é ambígua; a sua situação no futuro não é menos, pois ninguém sabe que sexo terá, nem quais são as suas hipóteses de sobreviver. Muitas vezes é vista como um ser simultaneamente perigoso e vulnerável. (...) É nos estados de transição que reside o perigo, pelo simples fato de toda a transição estar entre um estado e outro e ser indefinível (1991: 116-117).

A situação do cadáver-vivo é muito semelhante ao estado de liminariedade descrito por Douglas. E a preposição "em" contribui para a compreensão de que o cadáver-vivo não está nem aqui nem lá, ele é o meio-termo, o mais ou menos morto. Rodrigues também afirma, com relação à maneira como nossa sociedade percebe os fatos considerados ambíguos que:

(...) tudo o que representa o insólito, o estranho, o anormal, o que está à margem das normas, tudo o que é intersticial e ambíguo, tudo o que é anômalo, tudo o que é desestruturado, pré-estruturado e antiestruturado, tudo o que está a meio caminho entre o que é próximo e predizível e o que é longínquo e está fora de nossas preocupações, tudo o que está em nossa proximidade imediata e fora de nosso controle, é germe de insegurança, inquietação e terror: converte-se imediatamente em fonte de perigo. (2006: 60). 
Assim, a ambiguidade coloca em risco a estrutura social, quando se tem uma pessoa que está ao mesmo tempo viva e morta, geram-se medos e angústias quanto à definição de seu status ontológico e, como foi verificado por Lock (2000, 2002), sempre está presente o medo de um possível erro de diagnóstico, medo que aumenta ao ver que a pessoa, além de respirar, se mexe.

\section{Considerações Finais}

A concepção oficial, do ponto de vista médico e legal, em relação à morte encefálica propõe que esta seja a "verdadeira" morte, a definitiva, irreversível e precisa. Quando não há mais o cérebro, não há mais relação social, vida, nada. A morte encefálica é um conceito moderno construído cientificamente pelo campo médico que se tornou operacional e passou a classificar cadáveres-vivos - que antes seriam considerados em vida vegetativa, mas, ainda assim, vivos - enquanto mortos. Contudo, se este fato é aceito, ao menos formalmente, pelo campo médico, para os atores "leigos" nem sempre é tão claro. Um morto que tem o coração batendo abala profundamente nossas representações sobre morte. O modelo que tínhamos para classificar os mortos e os vivos é colocado em xeque. Com estas questões em mente fui a campo para verificar o que os médicos pensavam sobre a morte encefálica e, para minha surpresa, constatei que muitos também têm ideias "leigas" sobre este tema.

Alguns dos informantes inclusive contestaram o conceito de morte encefálica enquanto definidor de morte. Questões como não é morte biológica, não é a morte natural, é um assassinato consentido pela sociedade foram referidas pelos médicos que entrevistei. Mas, então, por que ela é legitimada científica e legalmente? Meus informantes respondem: a partir do momento em que se tem disponível tecnologia para que as cirurgias de transplantes possam ser rotinizadas, cria-se a demanda por órgãos e a necessidade de obtê-los. Isto talvez seja o grande deslize da morte encefálica: o seu caráter utilitário. Por um lado, os transplantes de órgãos legitimam a operacionalização deste conceito; como existe a possibilidade de substituir órgãos "danificados" e como isto pode salvar vidas, a morte encefálica passa a ser uma excelente perspectiva, que deve ser adota pela classe médica e, especialmente, pelos médicos que trabalham diretamente com transplantes de órgãos. Por outro lado, como é um critério tão ambíguo para definir morte e, como nasce com o interesse em obter órgãos, talvez, não se possa ter certeza se essa é a morte verdadeira ou apenas um meio para chegar a um determinado fim. 


\section{JULIANA LOPES DE MACEDO. AS REGRAS DO JOGO DA MORTE ENCEFÁLICA}

Apesar dos dois grupos de médicos entrevistados terem concepções semelhantes sobre a morte encefálica, a análise dos dados demonstrou que existem distinções que estão relacionadas com a posição que cada grupo ocupa no campo médico. O discurso dos intensivistas quanto às dúvidas que um cadáver-vivo gera é muito mais claro e direto, em comparação aos médicos pertencentes a equipes de transplantes.

A partir dos dados obtidos com este estudo é relevante, também, situar a morte encefálica dentro das concepções gerais de morte. Ariès (2002) e Elias (2001) afirmam que a morte na modernidade foi levada para os bastidores da vida social, não se trata mais de um acontecimento público, cotidiano e natural. Pelo contrário, hoje evitamos a morte a todo o custo. Morrer se tornou uma derrota. Aliado a este fato, temos a medicina e sua função soteriológica de proporcionar a cura, a salvação e a redenção (Good, 1993).

Se hoje a morte é uma derrota, o peso do fracasso é ainda maior para os médicos, pois são eles que têm a vocação, o conhecimento e a tecnologia para evitar ou, pelo menos, adiar a morte. Promessas médicas para isto não faltam: terapias com células-tronco, criopreservação e, até mesmo, clonagem. Porém, se a morte encefálica, por um lado, representa o fracasso da medicina em não "salvar" uma vida, por outro lado, a morte encefálica é uma maneira de "matar" a morte. Isto ocorre porque é por meio da morte encefálica que as cirurgias de transplantes de órgãos podem salvar a vida de outras pessoas. Conforme Lock (2000, 2002), os Estados Unidos estão anestesiados para o tema da morte encefálica, o único interesse relacionado ao assunto diz respeito aos transplantes de órgãos. Pode-se afirmar que no Brasil ocorre algo semelhante, e o problema é que não se discute de onde vêm os órgãos que são utilizados para transplantes. Sendo assim, se o cadáver-vivo incomoda, a morte encefálica soluciona o "problema" da morte moderna, pois a partir do momento em que o cadáver-vivo se transforma em um doador, não temos mais morte, e sim vida.

Tentei demonstrar que, assim como propõe Sahlins (2003), nada pode garantir que um determinado grupo social, dotado de inteligência, interesses e biografias sociais próprias interpretará um determinado fenômeno da mesma maneira que outros grupos de uma mesma sociedade. Assim, a morte encefálica tem diferentes significados para diferentes atores sociais. Nesse sentido, também pretendi contextualizar a morte encefálica enquanto um conceito produzido na esfera científica, demonstrando que esse conceito é datado e localizado social e historicamente. Portanto, a morte encefálica só faz sentido na sociedade moderna e ocidental, na qual a ciência tem uma posição central na definição de "verdades". 


\section{Notas}

${ }^{1}$ A própria Igreja Católica sustenta que a definição da morte é uma questão médica e não religiosa (Pio XII, 1958). Além disso, o Relatório Ad Hoc da Escola de Medicina de Harvard sobre a definição de morte cerebral (1998) cita casos jurídicos norte-americanos que também argumentam que a definição de morte é um tema médico.

${ }^{2}$ Como será demonstrado ao longo do artigo, a maneira de denominar o morto encefálico é bastante ambígua. Nesse momento, opto por tratá-lo da mesma forma como ele é tratado pelos autores citados na realização dessa revisão sobre morte encefálica, tendo em vista que o propósito nessa primeira seção do texto é demonstrar o contexto no qual o conceito de morte encefálica surge e a discussão médica em torno dele nesse período.

${ }^{3}$ Lock (2000) comenta a respeito de uma pesquisa realizada por médicos japoneses com pacientes em morte encefálica. Como no Japão o cadáver-vivo em morte encefálica permanece ligado aos equipamentos, visto que a morte encefálica não é uma definição de morte aceita por eles, os médicos puderam observar que pacientes nesse estado podem "sobreviver" por semanas ou até mesmo por meses.

${ }^{4}$ De acordo com Garcia et al. (2000) as principais causas de morte encefálica são: traumatismo craniano $(62,6 \%)$ - destes, $62,6 \%$ são ocasionados por acidentes de trânsito, 26,6\% por armas de fogo e $10,8 \%$ por outras causas -, acidente vascular cerebral (30,9\%), encefalopatia pós-anóxia (4,5\%), tumor cerebral primário $(1,4 \%)$, abscesso cerebral e/ou meningite $(0,3 \%)$ e anencefalia $(0,3 \%)$.

${ }^{5}$ Uma equipe intra-hospitalar de transplantes é responsável por fazer a mediação entre hospital e Central de Transplante Estadual. Nenhum dos membros pode fazer parte de equipes de transplantes de órgãos ou realizar diagnóstico de morte encefálica. Isto é exigido para não haver conflitos de interesse, pois é esta equipe que solicita às famílias a doação de órgãos.

${ }^{6}$ Outros testes que podem ser realizados para a comprovação de morte encefálica são: Angiografia Cerebral, Cintilografia Radioisotópica, Doppler Transcraniano, Monitorização da Pressão Intracraniana, Tomografia Computadorizada com Xenônio, Tomografia por Emissão de Fóton Único, Tomografia por Emissão de Pósitrons, Eletroencefalograma, Extração Cerebral de Oxigênio.

${ }^{7}$ Segundo Pessini e Barchifontaine, futilidade terapêutica é definida como o "prolongamento artificial da vida, para além do que seria o processo biológico comum” (2002: 295).

\section{Referências bibliográficas}

ArIÈs, Philippe

2003 História da morte no Ocidente. Rio de Janeiro, Ediouro.

Associação Brasileira de Transplantes de Órgãos

2006 Registro brasileiro de transplantes. 12(2).

BitencourT, Almir Galvão, et al.

2007 "Avaliação do conhecimento de estudantes de medicina sobre morte encefálica”.

Revista Brasileira de Terapia Intensiva, 19(2): 144-150. 


\section{JULIANA LOPES DE MACEDO. AS REGRAS DO JOGO DA MORTE ENCEFÁLICA}

\section{Conselho Federal de Medicina}

1997 Resolução 1.480 de 08 de agosto de 1997. Dispõe sobre os critérios para definição de morte encefálica.

2007 Resolução 1.826 de 06 de dezembro de 2007. Dispõe sobre a legalidade e o caráter ético da suspensão dos procedimentos de suportes terapêuticos quando da determinação de morte encefálica de indivíduo não-doador.

Douglas, Mary

1991 Pureza e perigo. Lisboa, Edições 70.

DuMONT, Louis

1985 O individualismo: uma perspectiva antropológica da ideologia moderna. Rio de Janeiro, Rocco.

ELIAS, Norbert

2001 A solidão dos moribundos. Rio de Janeiro, Jorge Zahar.

GARCIA, Valter Duro, et al.

2000 "Avaliação dos dez anos de atividades da coordenação de transplantes do Rs". In - (orgs.), Por uma politica de transplantes no Brasil. São Paulo, Office Editora e

Publicidade Ltda, pp. 36-96.

Good, Byron J.

1993 “How Medicine Construct Its Objects". In . (Org.), Medicine, Rationality and Experience - An Anthropological Perspective. Cambridge, Cambridge University Press, pp. 65-87.

KANDEL, Liliane

1987 "Reflexões sobre o uso da entrevista, especialmente a não-diretiva, e sobre as pesquisas de opinião”. In THiollen, M. (org.), Crítica metodológica, investigação social e enquete operária. São Paulo, Editora Polis, pp. 169-189.

\section{Lima, Cristina}

2005 "Do conceito ao diagnóstico de morte: controvérsias e dilemas éticos". Revista da Sociedade Portuguesa de Medicina Interna. 12(1): 6-10.

Lock, Margareth

2000 "On Dying Twice: Culture, Technology and the Determination of Death". In Lock, M.; Young, A. e Cambrosio, A. (orgs.). Living and Working the Nex Medical Tecnologies. 
Cambridge, Cambridge University Press, pp. 233-262.

2002 Twice Dead - Organ Transplats and the Reinvention of Death. California, University of California Press.

Menezes, Rachel Aisengart

2001 "Etnografia do Ensino Médico em um сті". Interface - Comunicação, Saúde e Educação, 5(9): 117-130.

Mollaret, Pierre e Goulon, Maurice

1959 “Le Coma dépassé (mémoire préliminaire)”. Revue Neurologique, 101(1), pp. 3-15.

Pessini, Leo e Barchifontaine, Christian de Paul de

2002 "Eutanásia e o direito a morrer com dignidade". In (orgs.), Problemas

atuais em Bioética. São Paulo, Edições Loyola, pp. 279-316.

PIO XII

1958 “The Prolongation of Life”. Pope Speaks, 4(4): 393-398.

Rodrigues, José Carlos

2006 Tabu da morte. Rio de Janeiro, Editora Fiocruz.

SAHLins, Marshall

2003 Ilhas de história. Rio de Janeiro, Jorge Zahar Editor.

SchePer-Huges, Nancy e BieHL, João Guilherme

2000 “O fim do corpo - comércio de órgãos para transplantes cirúrgicos”. In DEBERT,

Guita Grin e Goldstein, Donna (orgs.), Politicas do corpo e o curso da vida. São Paulo,

Editora Sumaré, pp. 49-81.

Shikida, Cláudio D. e Araújo Jr. Ari Francisco de

2004 Introdução à economia da alocação de órgãos para transplantes: direitos de propriedade, mercado de órgãos e filas de espera no Sistema Nacional de Transplantes. Disponível em: http://www.ceaee.ibmecmg.br/wp/wp15.pdf.

The Journal of the American Medical Association

1968 "A Definition of Irreversible Coma. Report of the Ad Hoc Committee of the Harvard Medical School to Examine the Definition of Brain Death". The Journal of the American Medical Association, 205 (6): 85-88. 
JULIANA LOPES DE MACEDO. AS REGRAS DO JOGO DA MORTE ENCEFÁLICA

Turner, Victor W.

1974 O processo ritual: estrutura e antiestrutura. Petrópolis, Vozes.

VAN GENNEP, Arnold

1978 Os ritos de passagem. Petrópolis, Vozes. 


\title{
Rules of the Game of Death Brain
}

\begin{abstract}
In 1968, the international medical community created the concept of "brain death", which is presently employed to refer to patients formerly referred to as in "irreversible coma". Since then, whenever a patient's brain shows no biological activity while his/her heart still works, the patient is said to be "brainly dead". For medicine, this implies not only the possibility of organ removal with transplant aims in mind; but also a new form of conceiving death. Based on semi-structured script interviews with medical doctors involved in this predicament, this article analyzes the process regarding brain death and the negotiations among the diverse social agents involved in the process of defining death.
\end{abstract}

KEYWORDS: Brain Death, Organ Transplant, Anthropology of Science.

Recebido em julho de 2014. Aceito em outubro de 2015. 